\title{
Formation of metallacarboxylic acids through Hieber base reaction. A density functional theory study
}

\author{
Shahbaz Ahmad ${ }^{1} \cdot$ Elisabeth A. Berry ${ }^{1} \cdot$ Conor H. Boyle ${ }^{1} \cdot$ Christopher G. Hudson $^{1} \cdot$ Oliver W. Ireland $^{1}$. \\ Emily A. Thompson ${ }^{1} \cdot$ Michael Bühl $^{1}$
}

Received: 7 November 2018 / Accepted: 19 December 2018 / Published online: 25 January 2019

(C) Springer-Verlag GmbH Germany, part of Springer Nature 2019

\begin{abstract}
Using density functional theory (B97-D/ECP2/PCM//RI-BP86/ECP1 level), we have studied the effects of ligand variation on $\mathrm{OH}^{-}$uptake by transition-metal carbonyls (Hieber base reaction), i.e., $\mathrm{L}_{n} \mathrm{M}(\mathrm{CO})+\mathrm{OH}^{-} \rightarrow\left[\mathrm{L}_{n} \mathrm{M}\left(\mathrm{CO}_{2} \mathrm{H}\right)\right]^{-}, \mathrm{M}=\mathrm{Fe}, \mathrm{Ru}, \mathrm{Os}, \mathrm{L}=$ $\mathrm{CO}, \mathrm{PMe}_{3}, \mathrm{PF}_{3}$, py, bipy, $\mathrm{Cl}, \mathrm{H}$. The viability of this step depends notably on the nature of the co-ligands, and a large span of driving forces is predicted, ranging from $\Delta \mathrm{G}=-144 \mathrm{~kJ} / \mathrm{mol}$ to $+122 \mathrm{~kJ} / \mathrm{mol}$. Based on evaluation of atomic charges from natural population analysis, it is the ability of the co-ligands to delocalize the additional negative charge (through their $\pi$-acidity) that is the key factor affecting the driving force for $\mathrm{OH}^{-}$uptake. Implications for the design of new catalysts for water gas shift reaction are discussed.
\end{abstract}

Keywords Homogeneous catalysis $\cdot$ Water gas shift reaction $\cdot$ Hieber base reaction $\cdot$ Density functional theory

\section{Introduction}

Hydrogen is the cleanest fuel and a cost-effective energy carrier of the future [1-6], which produces three times more energy per unit mass than fossil fuels [7]. Industrially, hydrogen is generated from fossil fuels releasing higher amounts of greenhouse gas, $\mathrm{CO}_{2}[8,9]$. A sustainable supply of hydrogen from renewable resources, such as biomass, is highly desirable $[4,10]$. Development of homogeneous transition metal catalysts for complete decomposition of polyhydroxy biomass constituents, i.e., carbohydrates, into $\mathrm{H}_{2}$ and $\mathrm{CO}_{2}$, could revolutionize $\mathrm{H}_{2}$ production from renewable resources. Methanol is the simplest model for such carbohydrates,

Dedicated to Prof. Tim Clark on the occasion of his 70th birthday

This paper belongs to the Topical Collection Tim Clark 70th Birthday Festschrift

Electronic supplementary material The online version of this article (https://doi.org/10.1007/s00894-018-3915-1) contains supplementary material, which is available to authorized users.

Michael Bühl

buehl@st-andrews.ac.uk

1 School of Chemistry, University of St Andrews, North Haugh, St Andrews, Fife KY16 9ST, UK but complete dehydrogenation of this compound according to

$\mathrm{MeOH}+\mathrm{H}_{2} \mathrm{O} \rightarrow 3 \mathrm{H}_{2}+\mathrm{CO}_{2}$

would be of considerable interest in its own right. This decomposition of methanol could follow a sequence of three reactions, (i) dehydrogenation, (ii) decarbonylation, and (iii) water-gas shift reaction (WGSR, see Scheme 1), all of which are well known.

Development of homogeneous transition metal catalysts for $\mathrm{H}_{2}$ production from methanol $[11,12]$ has attracted much attention in the past few decades. Morton and Cole-Hamilton developed a ruthenium catalyst $\left[\mathrm{Ru}(\mathrm{H})_{2}\left(\mathrm{X}_{2}\right)\left(\mathrm{PPh}_{3}\right)_{3}\right](\mathrm{X}=\mathrm{N}$, $\mathrm{H})$ for partial dehydrogenation of alcohols (including methanol) with notable turnover frequencies [13]. Aldehydes and ketones were the main products [formaldehyde in case of methanol, Scheme 1, step (i)]. During the conversion of ethanol, significant amounts of methane and a carbonyl complex, $\left[\mathrm{RuH}_{2}(\mathrm{CO})\left(\mathrm{PPh}_{3}\right)_{3}\right]$, were produced through decarbonylation [Scheme 1, step (ii)]. However, since no $\mathrm{CO}_{2}$ was noticed, apparently these Ru complexes are not active as WGSR catalysts [14].

Recently, based on density functional theory (DFT) calculations, we studied the mechanisms for the dehydrogenation [15] and decarbonylation [16] of aliphatic alcohols catalyzed by the Morton and Cole-Hamilton system, $\left[\mathrm{RuH}_{2}\left(\mathrm{H}_{2}\right)\left(\mathrm{PPh}_{3}\right)_{3}\right]$ 
Scheme 1 Putative reaction sequence for complete methanol dehydrogenation

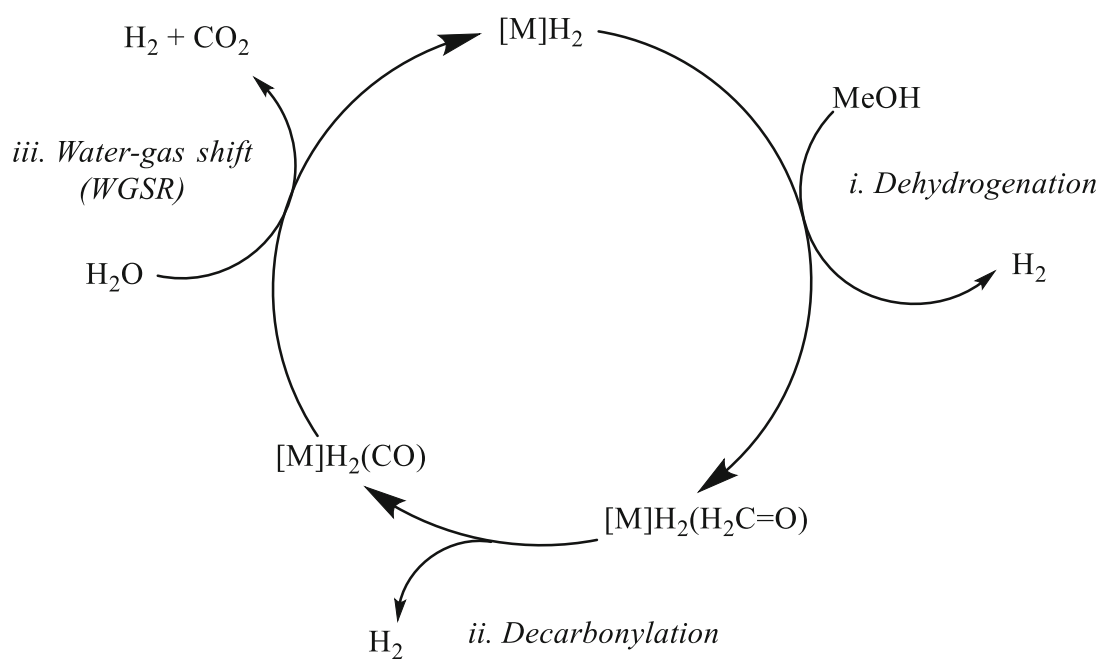

[Scheme 1, steps (i) and (ii)]. When exploring the feasibility of WGSR with these complexes computationally [17], we noticed that the first step of WGSR, the attack of water (in the form of $\mathrm{OH}^{-}$) on the $\mathrm{CO}$ ligand (Scheme 2) is highly endergonic.

Significant research has been undertaken to reveal the mechanism of WGSRs catalyzed by homogeneous transition metal complexes, particularly the metal carbonyls of $\mathrm{Fe}, \mathrm{Ru}$, and Os [18-30]. Recently, Guo et al. have studied the WGSR mechanism catalyzed by hexacarbonyl complexes of Mo and $\mathrm{W}$ [31]. In all of these reactions, which are conducted under basic conditions, $\mathrm{OH}^{-}$is the nucleophile and its uptake to form a transient metallacarboxylic acid is considered as the initial step (in the grey box in Scheme 2). Such attack of $\mathrm{OH}^{-}$on carbonyl ligands is well known as Hieber base reaction [32].

In all studies of metal carbonyl catalyzed WGSR, this $\mathrm{OH}^{-}$ uptake appeared to be highly exothermic and essentially

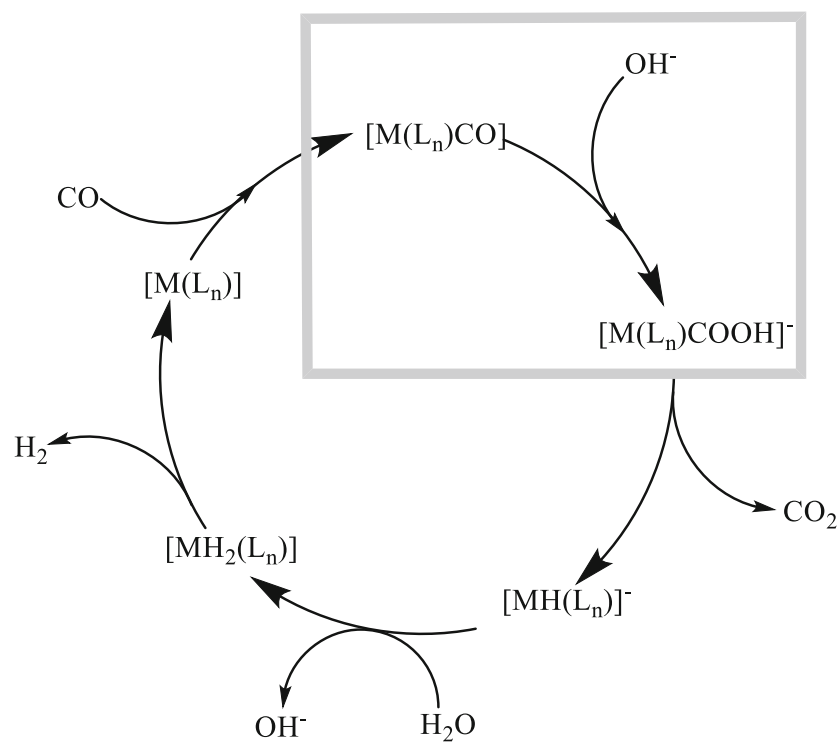

Scheme 2 General mechanism for transition-metal-catalyzed WGSR under basic conditions, where $\mathrm{OH}^{-}$is the nucleophile barrierless. In contrast, in our study of WGSR in the Morton and Cole-Hamilton system [17], this step is predicted to be highly endergonic. The driving force for formation of the metallacarboxylic acid depends notably on the co-ligands that are present, in particular on the number of CO ligands. While large negative enthalpies and free energies are computed for the $\mathrm{OH}^{-}$uptake of $\mathrm{Ru}(\mathrm{CO})_{5}[28,29] \Delta \mathrm{G}=127.7 \mathrm{~kJ} / \mathrm{mol}$ and $81.6 \mathrm{~kJ} / \mathrm{mol}$ are predicted for $\left[\mathrm{RuH}_{2}(\mathrm{CO})\left(\mathrm{PPh}_{3}\right)_{3}\right]$ and $\left[\mathrm{RuH}_{2}(\mathrm{CO})_{2}\left(\mathrm{PPh}_{3}\right)_{2}\right]$, respectively. It therefore appears that suitable ligand design, by varying the steric or electronic properties of the ligands, could make the process of $\mathrm{OH}^{-}$uptake feasible. In this work, we now report DFT-computed driving forces for $\mathrm{OH}^{-}$uptake in a number of metal-carbonyl complexes of $\mathrm{Ru}, \mathrm{Fe}$, and Os. Along with $\mathrm{CO}$, we have made the choice of trimethylphosphine (comparable to triphenylphosphine), trifluorophosphine (a strong $\pi$-acceptor ligand, comparable to $\mathrm{CO}$ ) [33], pyridine, and bipyridine ligands. For a perfect catalytic system, the $\mathrm{OH}^{-}$entry into the cycle should be facile and should not produce a very lowlying intermediate on the reaction profile that would eventually deactivate the catalytic system. This work can lead to the rational design of better catalysts for WGSR and, eventually, towards the complete decomposition of alcohols by dehydrogenation, decarbonylation, and the finally WGSR, which could facilitate entry into a hydrogen-based economy.

\section{Results and discussion}

\section{Ligand effects on the initial uptake of $\mathrm{OH}^{-}$to form the metallacarboxylic acid}

In metal carbonyls, $\mathrm{OH}^{-}$uptake is usually considered a fast process, and the resulting metallacarboxylic acid is usually too reactive to be isolated and decarboxylates under $\mathrm{CO}_{2}$ evolution to form a hydride (Scheme 2). Protonation of this hydride 
intermediate takes the system uphill on the free energy reaction profile and the $\mathrm{H}_{2}$ evolution tends to be associated with the highest energy transition state. Our work focuses on the ligand effects on the initial uptake of $\mathrm{OH}^{-}$to metal carbonyls (Eq. 2, corresponding to the first step in the grey box in Scheme 2), taking $\mathrm{M}(\mathrm{CO})_{5}$ pentacarbonyls as prototypical representatives ( $\mathrm{M}=\mathrm{Fe}, \mathrm{Ru}, \mathrm{Os})$. Step by step, we replaced each of the $\mathrm{CO}$ in the metal pentacarbonyl system with selected ligands, namely trimethylphosphine $\left(\mathrm{PMe}_{3}\right)$, trifluorophosphine $\left(\mathrm{PF}_{3}\right)$, pyridine (py), and bipyridine (bipy). We compared the free energies of the reactants (metal carbonyls) and the products (metallacarboxylic acids) to see how such a ligand change affects the driving force for the $\mathrm{OH}$ - uptake to the system. We have included the results for $\mathrm{Ru}$ carbonyls and metallacarboxylic acids in the main paper, whereas the results for the $\mathrm{Fe}$ and Os analogs are included within the supporting information (SI).

$$
\begin{aligned}
& \mathrm{L}_{n} \mathrm{M}(\mathrm{CO})+\mathrm{OH}^{-} \rightarrow\left[\mathrm{L}_{\mathrm{n}} \mathrm{M}\left(\mathrm{CO}_{2} \mathrm{H}\right)\right]^{-}, \mathrm{M}=\mathrm{Fe}, \mathrm{Ru}, \mathrm{Os}, \mathrm{L} \\
& \quad=\mathrm{CO}, \mathrm{PMe}_{3}, \mathrm{PF}_{3}, \text { py, bipy, } \mathrm{Cl}, \mathrm{H}
\end{aligned}
$$

Unlike $\mathrm{CO}, \mathrm{PMe}_{3}$ is a weak $\pi$-acceptor ligand and experiences weak backbonding with the metal center. At our chosen level of theory, B97-D/ECP2//RI-BP86/ECP1, Ru(CO) $)_{5}$ has a driving force of $\Delta \mathrm{G}=-93.5 \mathrm{~kJ} / \mathrm{mol}$ for the initial $\mathrm{OH}^{-}$uptake. This driving force decreases (i.e., $\Delta \mathrm{G}$ increases) as we increase the number of $\mathrm{PMe}_{3}$ ligands that replace $\mathrm{CO}$. On substituting one $\mathrm{CO}$ with one $\mathrm{PMe}_{3}$ ligand at the axial position, the free energy increases to $-38.9 \mathrm{~kJ} / \mathrm{mol}$, which further increases to $49.2 \mathrm{~kJ} / \mathrm{mol}$ on replacing the second $\mathrm{CO}$ on the axial position with another $\mathrm{PMe}_{3}$ ligand [34]. The $\mathrm{OH}^{-}$uptake to $\mathrm{Ru}(\mathrm{CO})_{2}\left(\mathrm{PMe}_{3}\right)_{3}$ is unfavorable by a free energy of $87.8 \mathrm{~kJ} /$ $\mathrm{mol}$, that of $\mathrm{Ru}(\mathrm{CO})\left(\mathrm{PMe}_{3}\right)_{4}$ by $122.2 \mathrm{~kJ} / \mathrm{mol}$ (Fig. 1). Since the subsequent steps on the WGSR reaction profile (Scheme 2) add additional barriers, the latter two complexes are expected to be only weakly active or unproductive as WGSR catalysts.

Based on the results obtained for the $\mathrm{PMe}_{3}$ ligand exchange with $\mathrm{CO}$, one can assume that the driving force for the $\mathrm{OH}^{-}$ uptake should be affected by replacing CO ligands with ligands of slightly greater $\pi$-acceptor strength, e.g., $\mathrm{PF}_{3}$. A slight increase of the driving force for $\mathrm{OH}^{-}$uptake is observed on replacing one $\mathrm{CO}$ at the axial position with a $\mathrm{PF}_{3}$ ligand, from $-93.5 \mathrm{~kJ} / \mathrm{mol}$ in $\mathrm{Ru}(\mathrm{CO})_{5}$ (Fig. 1) to $-101.8 \mathrm{~kJ} / \mathrm{mol}$ for $\mathrm{Ru}(\mathrm{CO})_{4}\left(\mathrm{PF}_{3}\right)$ (Fig. 2). On exchanging both axial $\mathrm{CO}$ ligands with $\mathrm{PF}_{3}$, the free energy decreases by $31.7 \mathrm{~kJ} / \mathrm{mol}$ for the $\mathrm{OH}^{-}$uptake as compared to the free energy of the $\mathrm{OH}^{-}$uptake in $\mathrm{Ru}(\mathrm{CO})_{5}$. One would expect that exchanging three $\mathrm{CO}$ ligands, two at the axial and one at the equatorial position, should further favor $\mathrm{OH}^{-}$uptake, but this is not the case. After the $\mathrm{OH}^{-}$uptake by $\mathrm{Ru}(\mathrm{CO})_{2}\left(\mathrm{PF}_{3}\right)_{3}$, the metalla-acid, $\left[\mathrm{Ru}(\mathrm{CO})(\mathrm{COOH})\left(\mathrm{PF}_{3}\right)_{3}\right]^{-}$, is obtained with a free energy of
Fig. 1 Computed free energies (B97-D level, $\mathrm{kJ} / \mathrm{mol}$ ) for the $\mathrm{OH}^{-}$uptake of the carbonyl reactant (note that this reactant is different for each product). The number of $\mathrm{PMe}_{3}$ ligands increases from left to right (see Fig. S1 in the ESI for a plot showing threedimensional representations of the complexes)

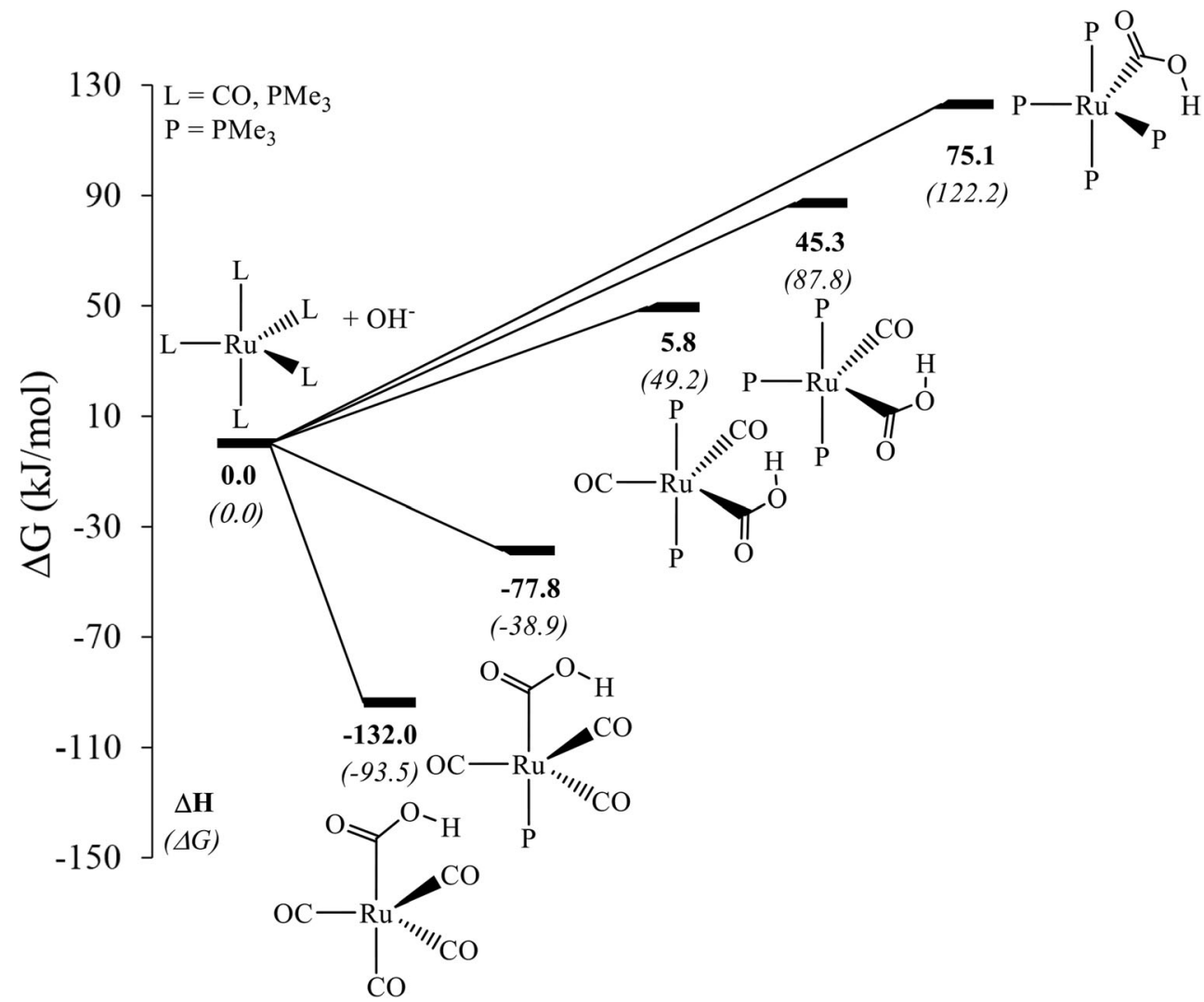


Fig. 2 Relative free energy ( $\mathrm{kJ} /$ mol) for the $\mathrm{OH}^{-}$uptake with that of the respective carbonyl reactant set to $0.0 \mathrm{~kJ} / \mathrm{mol}$ in each case. The number of $\mathrm{PF}_{3}$ ligands increases from left to right (see Fig. S2 in the ESI for a plot showing threedimensional representations of the complexes)

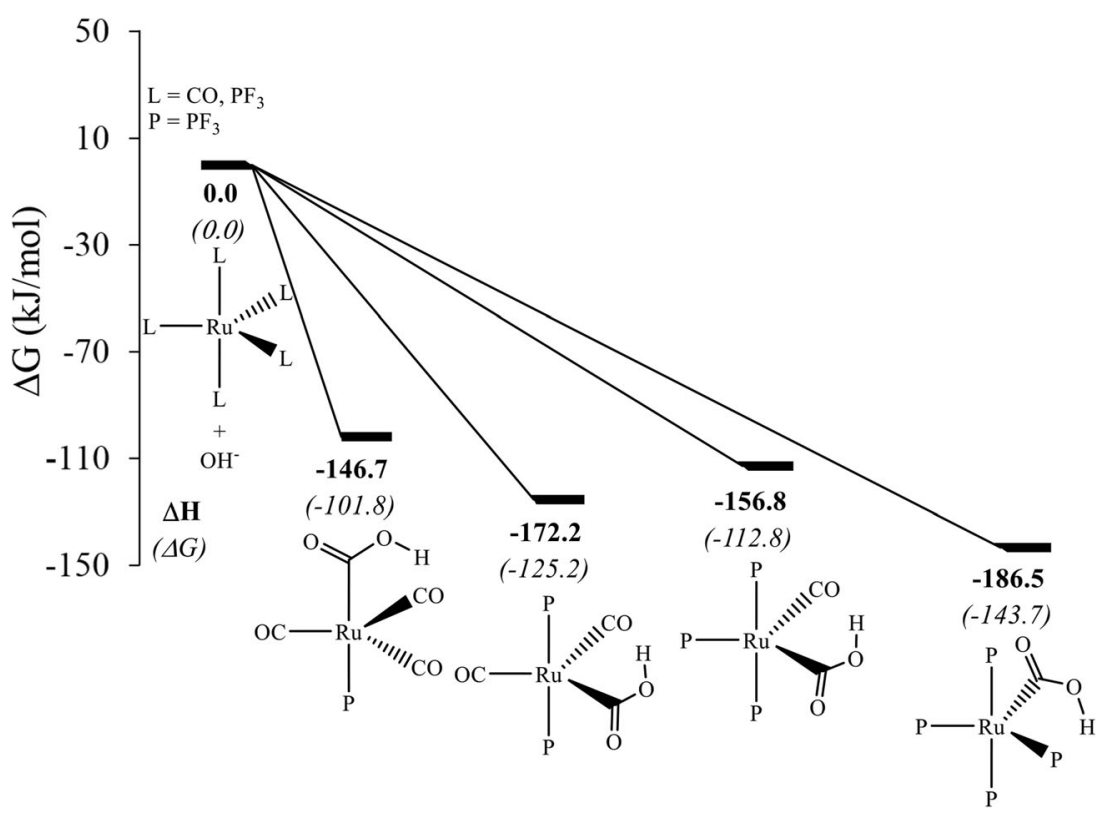

$-112.8 \mathrm{~kJ} / \mathrm{mol}$, which is higher by $12.5 \mathrm{~kJ} / \mathrm{mol}$ than the free energy for the $\mathrm{OH}^{-}$uptake in $\mathrm{Ru}(\mathrm{CO})_{2}\left(\mathrm{PF}_{3}\right)_{3}$, possibly because of the trans influence of $\mathrm{CO}$. When employing another, higher-lying isomer of $\mathrm{Ru}(\mathrm{CO})_{2}\left(\mathrm{PF}_{3}\right)_{3}$, where one of the $\mathrm{CO}$ ligands is positioned trans to $\mathrm{PF}_{3}$, the resulting metalla-acid is obtained at a $\Delta \mathrm{G}$ of $-121.4 \mathrm{~kJ} / \mathrm{mol}$. This value is lower by $8.6 \mathrm{~kJ} / \mathrm{mol}$ compared to the $\Delta \mathrm{G}$ for the most stable isomer included in Fig. 2. There is thus a noticeable trans influence on the driving force under scrutiny, although it does not seem to override other electronic effects.

$\mathrm{Ru}(\mathrm{CO})\left(\mathrm{PF}_{3}\right)_{4}$ follows the expected trend in terms of free energy for the $\mathrm{OH}^{-}$uptake and has the largest predicted affinity for $\mathrm{OH}^{-}$of all complexes studied here $(-143.7 \mathrm{~kJ} / \mathrm{mol}$, Fig. 2). It should be noted that such a large driving force for $\mathrm{OH}^{-}$ uptake does not necessarily make this complex a good target for a WGSR catalyst, because a correspondingly higher energy needs to be invested to close the cycle and re-form the initial catalyst.

A variety of $[\mathrm{Ru}]-\mathrm{CO}_{2} \mathrm{H}$ complexes are known, some of which have been structurally characterized, notably with bidentate aromatic $\mathrm{N}$-donor ligands $[35,36]$. We therefore included a couple of model complexes with aromatic Ndonor ligands, namely pyridine (py) and bipy. Both are coordinated through the lone pair of an electronegative $\mathrm{N}$ atom providing inductive donation, with the aromatic backbone allowing for significant $\pi$-backbonding interaction. As the inductive donation from the nitrogen lone pair is counteracted by the backbonding into the aromatic system, on exchanging one $\mathrm{CO}$ at the axial position in $\mathrm{Ru}(\mathrm{CO})_{5}$ with a pyridine (py), the $\mathrm{OH}^{-}$uptake becomes unfavorable as compared to that in parent $\mathrm{Ru}(\mathrm{CO})_{5}$, but not by that much as in case of $\mathrm{PMe}_{3}$ ligand. On replacing two $\mathrm{CO}$ with a bipy bidentate ligand, the $\mathrm{OH}^{-}$uptake becomes further unfavorable as compared to that in parent $\mathrm{Ru}(\mathrm{CO})_{5}$, but remains favorable by $63.4 \mathrm{~kJ} / \mathrm{mol}$ as compared to the $\mathrm{OH}^{-}$uptake in the $\mathrm{Ru}(\mathrm{CO})_{3}\left(\mathrm{PMe}_{3}\right)_{2}$ system (Fig. 3).

Finally, in addition to the pentacoordinate $\mathrm{Ru}(0)$ species, we considered the $\mathrm{OH}^{-}$uptake in a few selected octahedral $\mathrm{Ru}(\mathrm{II})$ complexes including $\mathrm{Ru}(\mathrm{CO})(\mathrm{H})_{2}\left(\mathrm{PMe}_{3}\right)_{3}$, $\mathrm{Ru}(\mathrm{CO})(\mathrm{H})_{2}\left(\mathrm{PF}_{3}\right)_{3}$, and $\left[\mathrm{Ru}(\mathrm{CO})_{3} \mathrm{Cl}_{3}\right]^{-}$(Fig. 4). The driving force for $\mathrm{OH}^{-}$uptake in $\mathrm{Ru}(\mathrm{CO})(\mathrm{H})_{2}\left(\mathrm{PMe}_{3}\right)_{3}$, endergonic by $82.7 \mathrm{~kJ} / \mathrm{mol}$, is comparable to that in the Morton and Cole-

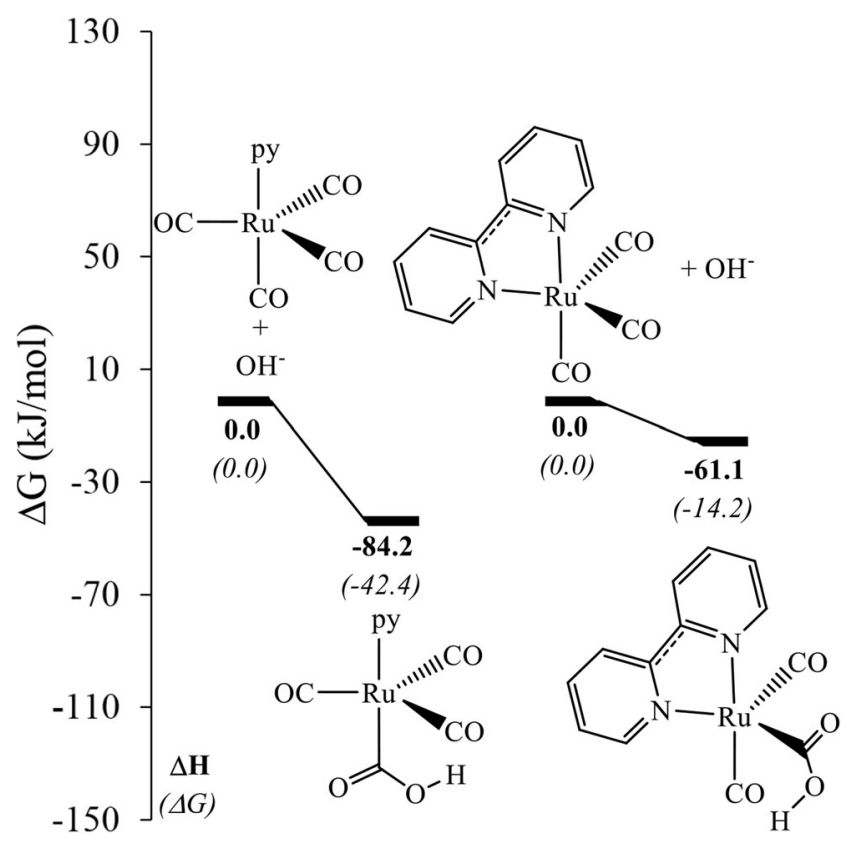

Fig. 3 Relative free energy $(\mathrm{kJ} / \mathrm{mol})$ for the $\mathrm{OH}^{-}$uptake on replacing one CO ligand with py (left) and two CO ligands with bipy (right) (see Fig. S3 in the ESI for a plot showing three-dimensional representations of the complexes) 
$\mathrm{L}=\mathrm{CO}, \mathrm{PMe}_{3}, \mathrm{PF}_{3}, \mathrm{H}, \mathrm{Cl}$

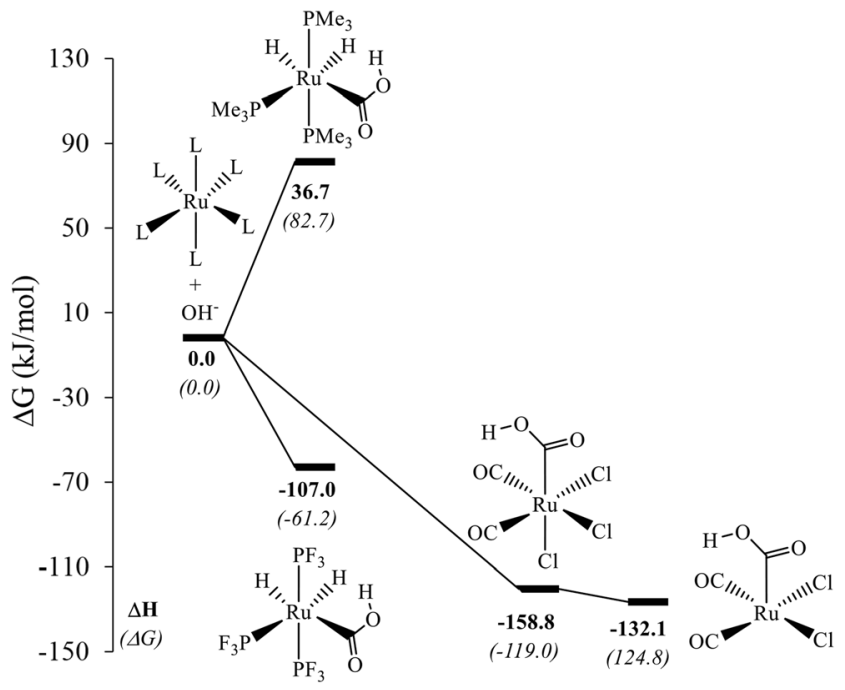

Fig. 4 Relative free energy $(\mathrm{kJ} / \mathrm{mol})$ for the $\mathrm{OH}^{-}$uptake with that of the respective octahedral carbonyl reactant set to $0.0 \mathrm{~kJ} / \mathrm{mol}$ in each case (see Fig. S4 in the ESI for a plot showing three-dimensional representations of the complexes)

Hamilton system, $\mathrm{Ru}(\mathrm{CO})(\mathrm{H})_{2}\left(\mathrm{PPh}_{3}\right)_{3}$, where it is endergonic by $127 \mathrm{~kJ} / \mathrm{mol}$ at essentially the same level (at a higher temperature, however, $150{ }^{\circ} \mathrm{C}$ ) $[17,37]$. On replacing $\mathrm{PMe}_{3} \mathrm{li}-$ gands with $\mathrm{PF}_{3}$ ligands, the product is obtained at a free energy of $-61.2 \mathrm{~kJ} / \mathrm{mol}$, obviously because of strong $\pi$ backbonding interaction.

The results for the analogous Os complexes are very similar to those for the Ru species just discussed, with individual driving forces for $\mathrm{OH}^{-}$uptake within typically $10 \mathrm{~kJ} / \mathrm{mol}$ of each other (ca. $20 \mathrm{~kJ} / \mathrm{mol}$ for the bipy complex, compare Tables S1 and S3 in the SI). On going from Ru to Fe congeners, the changes in this driving force become somewhat more variable (up to ca. $30 \mathrm{~kJ} / \mathrm{mol}$, compare Tables S1 and S2 in the $\mathrm{SI})$, but overall the same trends are obtained irrespective of the group 8 metal.

The metallacarboxylic acid arising from Hieber base reaction of $\left[\mathrm{Ru}(\mathrm{CO})_{3} \mathrm{Cl}_{3}\right]^{-}$has been implicated as a key reactive intermediate in a complex variety of reactions [32]. Indeed, despite forming a dianion from two monoions, $\mathrm{OH}^{-}$uptake of $\left[\mathrm{Ru}(\mathrm{CO})_{3} \mathrm{Cl}_{3}\right]^{-}$affording $\left[\mathrm{Ru}(\mathrm{CO})_{2}\left(\mathrm{CO}_{2} \mathrm{H}\right) \mathrm{Cl}_{3}\right]^{2-}$ is highly exergonic, with a free energy of $-119.0 \mathrm{~kJ} / \mathrm{mol}$. This large driving force is fully consistent with the fact that this complex is a reactive intermediate that can be formed through Hieber base reaction [32]. Experimentally, $\left[\mathrm{Ru}(\mathrm{CO})_{2}\left(\mathrm{CO}_{2} \mathrm{H}\right) \mathrm{Cl}_{3}\right]^{2-}$ appears to lose a chloride ion consistent with our calculations as at our level, as this process is computed to be slightly exergonic, by $-5.9 \mathrm{~kJ} / \mathrm{mol}$.

\section{Natural population analysis}

What is the origin of the huge variation in driving forces for $\mathrm{OH}^{-}$uptake in these complexes? Hypothesizing that a key factor should be delocalization of the additional negative charge brought into the complex, we used natural population analysis (NPA) [38] to evaluate the extent of charge transfer from $\mathrm{OH}^{-}$upon attack on the carbonyl ligand. To this end, we simply calculated the natural charge on the $\mathrm{OH}^{-}$fragments in the ruthenacarboxylic acid products, assessing how it changes from the value in free $\mathrm{OH}^{-}$, where it is -1 . A substantial reduction from this absolute value is found in the complexes, indicating that most of the charge is actually delocalized into the complex, but there is still a notable variation of this charge, between -0.32 and -0.19 (see Table S4 in the SI).

The $\mathrm{PMe}_{3}$ ligand has $\sigma$-donating abilities, which pushes electron density to the metal center, which increases the amount of backbonding interaction between the filled metal $d$-orbital and the empty $\pi^{*}$ - orbital of the carbon atom of CO. The overall affect makes it difficult for the $\mathrm{OH}^{-}$fragment to delocalize electron density over the metal complex. As we replace more $\mathrm{CO}$ ligands with $\mathrm{PMe}_{3}$ ligands, the natural charge at the $\mathrm{OH}^{-}$fragment decreases. In $\left[\mathrm{Ru}(\mathrm{CO})_{2}\left(\mathrm{CO}_{2} \mathrm{H}\right)\left(\mathrm{PMe}_{3}\right)_{2}\right]^{-}$, presence of a $\mathrm{CO}$ ligand at the axial position trans to the $-\mathrm{CO}_{2} \mathrm{H}^{-}$fragment increases its distance from the metal center, making it less available for $\mathrm{OH}^{-}$ fragment to accommodate the charge density. Here the trans influence dominates the electronic nature of the ligands and a small discrepancy in the natural charges of the $\mathrm{OH}^{-}$fragment occurs when we move from $\left[\mathrm{Ru}(\mathrm{CO})_{2}\left(\mathrm{CO}_{2} \mathrm{H}\right)\left(\mathrm{PMe}_{3}\right)_{2}\right]^{-}$to $\left[\mathrm{Ru}(\mathrm{CO})\left(\mathrm{CO}_{2} \mathrm{H}\right)\left(\mathrm{PMe}_{3}\right)_{3}\right]^{-}$, similar is the case with py and bipy ligands. For the $\mathrm{PF}_{3}$ ligands, on replacing each with the $\mathrm{CO}$ ligands, the natural charge at the $\mathrm{OH}^{-}$fragment gradually increases, as expected (Table S4).

A plot of the computed driving forces vs. $\mathrm{OH}^{-}$charges indeed reveals an overall trend towards more favorable $\mathrm{OH}^{-}$uptake with decreasing charge on this fragment (see Fig. 5; essentially the same correlation is obtained when enthalpies are used instead of free energies, see Fig. S5 in the SI). No strict relationship is apparent, and there are a few outliers, notably the bipy complex, but overall our results are consistent with the charge delocalization being a key factor for the driving force of this reaction step. For instance, the $\mathrm{PF}_{3}$ ligands, which are predicted to strongly promote Hieber base reaction (Fig. 2), are indicated to do so because they are very efficient in delocalizing the incoming negative charge (see red triangles in the lower right of Fig. 5). Arguably, the extent of this charge delocalization will depend on the balance between $\sigma$-donating and $\pi$ backdonating capabilities of the co-ligands, which should allow for a rational tailoring of complexes toward Hieber base reaction and, eventually, for designing new WGSR catalysts.

\section{Conclusions}

In summary, using an appropriate DFT level, we have computed the driving forces for formation of metallacarboxylic 
Fig. 5 Plot of driving forces for $\mathrm{OH}^{-}$uptake vs. natural charges of the $\mathrm{OH}^{-}$fragments in the products (B97-D level)

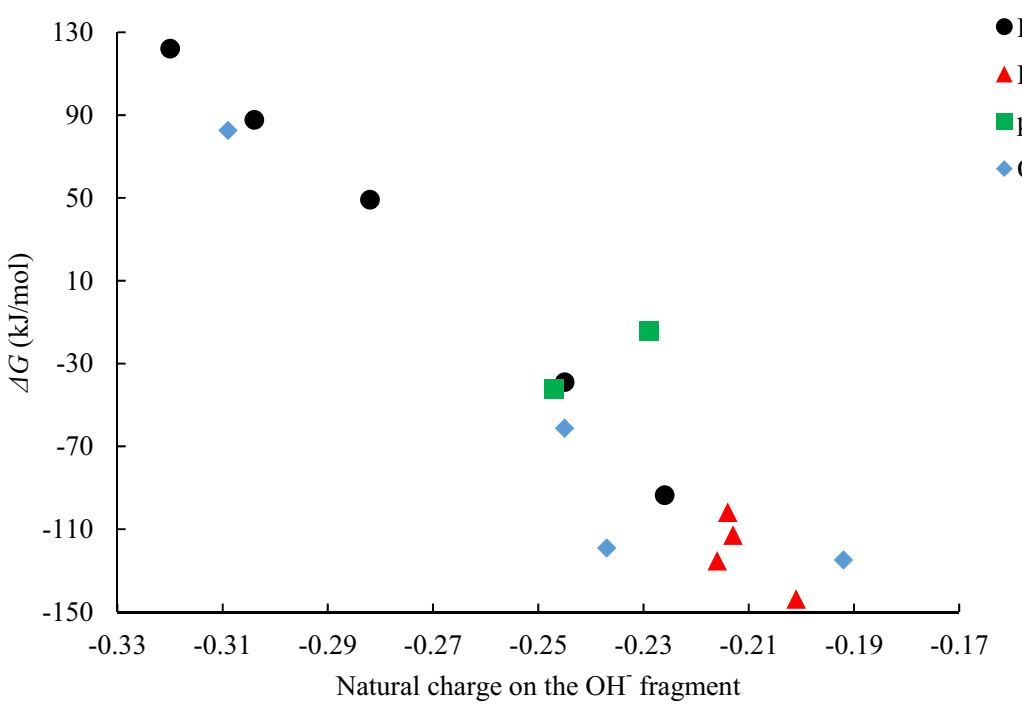

- $\mathrm{PMe}_{3}$ Ligands

$\triangle \mathrm{PF}_{3}$ Ligands

-py and bipy Ligands

$\rightarrow$ Octahedral Complexes acids from group 8 carbonyl complexes through uptake of $\mathrm{OH}^{-}$. This reaction (Eq. 2), known as Hieber base reaction, is the first step of water-gas shift reaction (WGSR) that can be catalyzed by transition metal complexes under basic conditions. According to our findings, the driving force for this step is surprisingly sensitive to the nature of the co-ligands at the metal, and can range from $\Delta \mathrm{G}=-144 \mathrm{~kJ} / \mathrm{mol}$ to $+122 \mathrm{~kJ} / \mathrm{mol}$ [for $\mathrm{R}=\mathrm{F}$ and $\mathrm{Me}$, respectively, in $\mathrm{Ru}(\mathrm{CO})\left(\mathrm{PR}_{3}\right)_{4}$ ]. Far from being innocent spectator ligands, these co-ligands actively take part in $\mathrm{OH}^{-}$uptake through delocalization of the negative charge, as apparent in the computed atomic charges from natural population analysis. Fe and Ru pentacarbonyls are prototypical WGSR catalysts; it is remarkable how replacement of CO ligands with electron-rich phosphines (which are ubiquitous in modern transition metal chemistry) can impede the first step of this WGSR catalytic cycle. In that case, use of phosphines with electron-withdrawing substituents (where we have used $\mathrm{PF}_{3}$ as extreme example) or aromatic N-donor ligands can increase the driving force for Hieber base reaction. Compared to these ligand effects, the nature of the metal (Fe, $\mathrm{Ru}$, or Os) or its oxidation state [e.g., $\mathrm{Ru}(0) \mathrm{vs}$. $\mathrm{Ru}(\mathrm{II})]$ seems to be of lesser importance for $\mathrm{OH}^{-}$uptake.

We are convinced that the tunability of the driving force for Hieber base reaction through appropriate choice of co-ligands can inform on the rational design of new WGSR catalysts. As this quantity, a simple reaction (free) energy, can be readily computed with modern DFT tools, large libraries of ligands can be screened computationally, opening up new avenues for applications of molecular modeling in homogeneous catalysis.

\section{Computational methodology}

In this work, we are mainly interested in calculating the driving force related to change in Gibbs free energy for the $\mathrm{OH}^{-}$ uptake, which is considered as the initial step of the WGSR. Our calculations follow a computationally cost-effective protocol based on density functional theory (DFT) that had been validated [39] and fruitfully applied to mechanistic DFT studies of related Ru complexes $[15,16]$. Geometry optimizations were carried out at a lower level, RI-BP86/ECP1, whereas the energies were refined at B97-D/ECP2 [40] level. All the metal complexes were fully optimized at the RI-BP86/ECP1 level, i.e., by the use of Becke [41] and Perdew [42] exchange and correlation functionals along with SDD [43] core potential and valence basis on the metal atoms, whereas all the other atoms were treated with the standard 6-31G(d,p) basis. The nature of all the minima was verified by frequency calculations within the harmonic approximation, which were further used to obtain the enthalpic and entropic corrections under standard conditions (1 atm and 298.15 K). Thermochemical correction terms $\delta E_{G}$ were obtained as:

$\delta E_{G}=\Delta G_{R I-B P 86 / E C P 1}-\Delta E_{R I-B P 86 / E C P 1}$

where $\Delta E_{R I-B P 86 / E C P 1}$ is the reaction energy and $\Delta G_{R I-B P 86 / E C P 1}$ is the corresponding Gibbs free energy (analogously for corrections to enthaly, $\delta E_{H}$ from $\left.\Delta H_{R I-B P 86 / E C P 1}-\Delta E_{R I-B P 86 / E C P 1}\right)$.

The energies of the optimized complexes were refined through single-point calculations at the B97-D/ECP2 level, i.e., using dispersion-corrected B97-D functional, which includes Grimme's dispersion correction [40] along with $6-311+\mathrm{G}(\mathrm{d}, \mathrm{p})$ basis set for all the nonmetal atoms (SDD on the metals). Solvent effects were included by a polarizable continuum model (PCM) [44, 45] using methanol as a model solvent with selfconsistent reaction field (SCRF) method. The solvent energy correction, $\delta E_{\text {solv }}$, was performed as:

$\delta E_{\text {solv }}=\Delta E_{P C M}-\Delta E$ 
Difference between the reaction energy in the continuum is donated as $\triangle E_{P C M}$ and $\triangle E$ is the difference between the reaction energy in gas phase at B97-D/ECP2 level. The final enthalpies and free energies, $\Delta H$ and $\Delta G$, were obtained as sum of all energy correction terms:

$$
\begin{aligned}
& \Delta H=\Delta E+\delta E_{\text {solv }}+\delta E_{H} \\
& \Delta G=\Delta E+\delta E_{\text {solv }}+\delta E_{G}
\end{aligned}
$$

where $\Delta E$ and $\delta E_{\text {solv }}$ were calculated at the B97-D/ECP2 level, whereas $\delta E_{\mathrm{H}}$ and $\delta E_{\mathrm{G}}$ were obtained at RI-BP86/ ECP1. Atomic charges from natural population analysis [38] were evaluated at the B97-D/ECP2/PCM level. All calculations were performed using the Gaussian 09 suite of programs [46].

In order to identify the most stable isomers and conformers of each reactant and product, an exhaustive screening of the possible stereoisomers was undertaken. Only the results for the most stable forms are reported. The conformation of the carboxylic acid group was uniformly taken as that where the hydrogen of the $\mathrm{OH}^{-}$fragment is pointing towards the metal center. We investigated the stability of these metalla-acids against those in which the hydrogen of the $\mathrm{OH}^{-}$fragments points away from the metal center, particularly in Fe complexes, the former complexes are appeared to be more stable (see Table S5).

Acknowledgements We thank EaStCHEM and the School of Chemistry for support. Computations were carried out on a local Opteron PC cluster maintained by Dr. H. Früchtl.

Open Access This article is distributed under the terms of the Creative Commons Attribution 4.0 International License (http:// creativecommons.org/licenses/by/4.0/), which permits unrestricted use, distribution, and reproduction in any medium, provided you give appropriate credit to the original author(s) and the source, provide a link to the Creative Commons license, and indicate if changes were made.

Publisher's note Springer Nature remains neutral with regard to jurisdictional claims in published maps and institutional affiliations.

\section{References}

1. Pena MA, Gomez JP, Fierro JLG (1996) New catalytic routes for syngas and hydrogen production. Appl Catal, A 144:7-57. https:// doi.org/10.1016/0926-860X(96)00108-1

2. Armor JN (1999) The multiple roles for catalysis in the production of H2. Appl Catal, A 176:159-176. https://doi.org/10.1016/S0926860X(98)00244-0

3. Trimm DL, Onsan ZI (2001) Onboard fuel conversion for hydrogen-fuel-cell-driven vehicles. Catal Rev - Sci Eng 43:3184. https://doi.org/10.1081/CR-100104386

4. Zhang YHP (2011) Hydrogen production from carbohydrates: a mini-review. ACS Symp Ser 1067 (Sustainable Production of Fuels, Chemicals, and Fibers from Forest Biomass):203-216. https://doi.org/10.1021/bk-2011-1067.ch008
5. Ricci M, Bellaby P, Flynn R (2008) What do we know about public perceptions and acceptance of hydrogen? A critical review and new case study evidence. Int. J. Hydrog. Energy 33:5868-5880. https:// doi.org/10.1016/j.ijhydene.2008.07.106

6. Momirlan M, Veziroglu T (1999) Recent directions of world hydrogen production. Renew. Sust. Energ. Rev. 3:219-231. https://doi. org/10.1016/S1364-0321(98)00017-3

7. Hemmes H, Driessen A, Griessen R (1986) Thermodynamic properties of hydrogen at pressures up to 1 mbar and temperatures between 100 and 1000 K. J. Phys. C Solid State Phys. 19:3571-3585. https://oi.org/10.1088/0022-3719/19/19/013

8. Navarro RM, Pena MA, Fierro JLG (2007) Hydrogen production reactions from carbon feedstocks: fossil fuels and biomass. Chem. Rev. 107:3952-3991. https://doi.org/10.1021/cr0501994

9. Veziroglu TN, Editor (1976) Conference Proceedings of the 1st World Hydrogen Energy conference, Vol. 1: March 1-3, 1976 Miami Beach, Fla. vol Copyright (C) 2018 American Chemical Society (ACS). All Rights Reserved. Univ. Miami Press,

10. Ishida Y, Kumabe K, Hata K, Tanifuji K, Hasegawa T, Kitagawa K, Isu N, Funahashi Y, Asai T (2009) Selective hydrogen generation from real biomass through hydrothermal reaction at relatively low temperatures. Biomass Bioenergy 33:8-13. https://doi.org/10.1016/ j.biombioe.2008.04.004

11. Sordakis K, Tang C, Vogt LK, Junge H, Dyson PJ, Beller M, Laurenczy G (2018) Homogeneous catalysis for sustainable hydrogen storage in formic acid and alcohols. Chem Rev (Washington, DC, US) 118:372-433. https://doi.org/10.1021/acs.chemrev. $7 \mathrm{~b} 00182$

12. Shen Y, Zhan Y, Li S, Ning F, Du Y, Huang Y, He T, Zhou X (2017) Hydrogen generation from methanol at near-room temperature. Chem. Sci. 8:7498-7504. https://doi.org/10.1039/C7SC01778B

13. Morton D, Cole-Hamilton DJ (1988) Molecular hydrogen complexes in catalysis: highly efficient hydrogen production from alcoholic substrates catalyzed by ruthenium complexes. J Chem Soc, Chem Commun:1154-1156. https://doi.org/10.1039/ c39880001154

14. Morton D, Cole-Hamilton DJ, Utuk ID, Paneque-Sosa M, LopezPoveda M (1989) Hydrogen production from ethanol catalyzed by group 8 metal complexes. J Chem Soc, Dalton Trans, pp 489-495

15. Sieffert N, Bühl M (2010) Hydrogen generation from alcohols catalyzed by ruthenium-triphenylphosphine complexes: multiple reaction pathways. J. Am. Chem. Soc. 132:8056-8070. https://doi.org/ $10.1021 / \mathrm{ja1} 01044 \mathrm{c}$

16. Sieffert N, Reocreux R, Lorusso P, Cole-Hamilton DJ, Bühl M (2014) On the importance of decarbonylation as a side-reaction in the ruthenium-catalysed dehydrogenation of alcohols: a combined experimental and density functional study. Chem. Eur. J. 20:41414155. https://doi.org/10.1002/chem.201303722

17. Lorusso P, Ahmad S, Schmid K, Cole-Hamilton DJ, Sieffert N, Bühl M Manuscript in preparation

18. Laine RM, Rinker RG, Ford PC (1977) Homogeneous catalysis by ruthenium carbonyl in alkaline solution: the water gas shift reaction. J. Am. Chem. Soc. 99:252-253. https://doi.org/10.1021/ ja00443a049

19. King RB, Frazier CC, Hanes RM, King Jr AD (1978) Active homogeneous catalysts for the water gas shift reaction derived from the simple mononuclear carbonyls of iron, chromium, molybdenum, and tungsten. J. Am. Chem. Soc. 100:2925-2927. https:// doi.org/10.1021/ja00477a076

20. Ford PC (1981) The water gas shift reaction: homogeneous catalysis by ruthenium and other metal carbonyls. Acc. Chem. Res. 14: 31-37. https://doi.org/10.1021/ar00062a001

21. Sunderlin LS, Squires RR (1993) Energetics and mechanism of the thermal decarboxylation of tetracarbonyl(carboxy)ferrate(1-) in the gas phase. J. Am. Chem. Soc. 115:337-343. https://doi.org/10. $1021 / \mathrm{ja} 00054 \mathrm{a} 048$ 
22. Torrent M, Sola M, Frenking G (1999) Theoretical study of gasphase reactions of $\mathrm{Fe}(\mathrm{CO}) 5$ with $\mathrm{OH}-$ and their relevance for the water gas shift reaction. Organometallics 18:2801-2812. https:// doi.org/10.1021/om9810504

23. King RB (1999) Homogeneous transition metal catalysis: from the water gas shift reaction to nuclear waste vitrification. J. Organomet. Chem. 586:2-17. https://doi.org/10.1016/S0022-328X(99)00155-2

24. Barrows SE (2004) Theoretical study of the gas-phase Fe(CO)5 catalyzed water gas shift reaction: a new mechanism proposed. Inorg. Chem. 43:8236-8238. https://doi.org/10.1021/ic049159t

25. Rozanska X, Vuilleumier R (2008) Mechanisms of the water-gasshift reaction by iron pentacarbonyl in the gas phase. Inorg. Chem. 47:8635-8640. https://doi.org/10.1021/ic8001866

26. Zhang F, Zhao L, Xu C, Chen Y (2010) Theoretical revisit of a $\mathrm{Fe}(\mathrm{CO})_{5}$-catalyzed water-gas shift reaction. Inorg. Chem. 49: 3278-3281. https://doi.org/10.1021/ic902148y

27. Chen Y, Zhang F, Xu C, Gao J, Zhai D, Zhao Z (2012) Theoretical investigation of water gas shift reaction catalyzed by iron group carbonyl complexes $\mathrm{M}(\mathrm{CO})_{5}(\mathrm{M}=\mathrm{Fe}, \mathrm{Ru}, \mathrm{Os})$. J. Phys. Chem. A 116:2529-2535. https://doi.org/10.1021/jp204776a

28. Schulz H, Goerling A, Hieringer W (2013) Mechanisms of the water-gas shift reaction catalyzed by ruthenium pentacarbonyl: a density functional theory study. Inorg. Chem. 52:4786-4794. https://doi.org/10.1021/ic301539q

29. Liu N, Guo L, Cao Z, Li W, Zheng X, Shi Y, Guo J, Xi Y (2016) Mechanisms of the water-gas shift reaction catalyzed by ruthenium carbonyl complexes. J. Phys. Chem. A 120:2408-2419. https://doi. org/10.1021/acs.jpca.6b00301

30. Schaper L-A, Herrmann WA, Kuehn FE Water-Gas Shift Reaction. In, 2018. Wiley-VCH Verlag GmbH \& Co. KGaA, pp 1689-1698. https://doi.org/10.1002/9783527651733.ch38

31. Guo L, Cao Z, Liu N, An X, Li A, Li W, Zheng X (2016) Mechanisms of the water-gas shift reaction catalyzed by carbonyl complexes $\mathrm{M}(\mathrm{CO})_{6}(\mathrm{M}=\mathrm{Mo}, \mathrm{W})$. Int. J. Hydrog. Energy 41:24322446. https://doi.org/10.1016/j.ijhydene.2015.11.108

32. Hill AF (2000) "simple" carbonyls of ruthenium: new avenues from the Hieber base reaction. Angew. Chem. Int. Ed. 39:130-133. https://doi.org/10.1002/(SICI)1521-3773(20000103)39:1<130:: AID-ANIE130>3.0.CO;2-6

33. Hill AF (2002) Organotransition metal chemistry. The Royal Society of Chemistry, Cambridge

34. $\mathrm{Ru}(\mathrm{CO})_{3}\left(\mathrm{PMe}_{3}\right)_{2}$, is a model for $\mathrm{Ru}(\mathrm{CO})_{3}\left(\mathrm{PPh}_{3}\right)_{2}$, , also known as Roper's catalyst: Cavit BE, Grundy KR, Roper WR (1972) Dicarbonyltris(triphenylphosphine)ruthenium and -osmium. Ethylene complex of ruthenium and a dioxygen complex of osmium. J Chem Soc, Chem Commun:60-61. https://doi.org/10.1039/ c3972000060b
35. e.g. $\left[\mathrm{Ru}(\text { phen })_{2}(\mathrm{CO})\left(\mathrm{CO}_{2} \mathrm{H}\right)\right]^{+}$(phen $=1,10$-phenanthroline): Gibson DH, Ding Y, Andino JG, Mashuta MS, Richardson JF (1998) Synthesis, Characterization, and Reactions of Ruthenium Phenanthroline Complexes Bearing C1 Ligands: Formyl, Metallocarboxylate, and $\mathrm{CO}_{2}$-Bridged Complexes. Organometallics 17:5178-5183. https://doi.org/10.1021/ OM9806242

36. e.g. $\left[\mathrm{Ru}(\text { bipy })_{2}(\mathrm{CO})\left(\mathrm{CO}_{2} \mathrm{H}\right)\right]^{+}$(bipy $=2,2^{\prime}=$ bipyridine): Toyohara K, Nagao H, Adachi T, Yoshida T, Tanaka K (1996) Crystal structure of $\left[\mathrm{Ru}(\mathrm{bpy})_{2}(\mathrm{CO})\left(\eta^{1}-\mathrm{C}(\mathrm{O}) \mathrm{OH}\right)\right]+\left(\mathrm{bpy}=2,2^{\prime}\right.$-bipyridine $)$ as a key intermediate in $\mathrm{CO}_{2} / \mathrm{CO}$ conversion. Chem Lett :27-28. https:// doi.org/10.1246/cl.1996.27

37. In terms of reaction enthalpies (i.e. without the temperaturedependent entropy part) the driving forces are $\Delta \mathrm{H}=36.7 \mathrm{~kJ} / \mathrm{mol}$ and $33.0 \mathrm{~kJ} / \mathrm{mol}$ for $\mathrm{PMe}_{3}$ and $\mathrm{PPh}_{3}$, respectively. These values are thus rather similar for both phosphines, indicating little steric hindrance with the bulkier $\mathrm{PPh} 3$

38. Reed AE, Weinstock RB, Weinhold F (1985) Natural population analysis. J. Chem. Phys. 83:735-746. https://doi.org/10.1063/1. 449486

39. Sieffert N, Bühl M (2009) Noncovalent interactions in a transitionmetal triphenylphosphine complex: a density functional case study. Inorg. Chem. 48:4622-4624. https://doi.org/10.1021/ic900347e

40. Grimme S (2006) Semiempirical GGA-type density functional constructed with a long-range dispersion correction. J. Comput. Chem. 27:1787-1799. https://doi.org/10.1002/jcc.20495

41. Becke AD (1988) Density-functional exchange-energy approximation with correct asymptotic behavior. Phys Rev A: Gen Phys 38: 3098-3100. https://doi.org/10.1103/PhysRevA.38.3098

42. Perdew JP (1986) Density-functional approximation for the correlation energy of the inhomogeneous electron gas. Phys. Rev. B Condens. Matter 33:8822-8824. https://doi.org/10.1103/ PhysRevB.33.8822

43. Andrae D, Haeussermann U, Dolg M, Stoll H, Preuss H (1990) Energy-adjusted ab initio pseudopotentials for the second and third row transition elements. Theor. Chim. Acta 77:123-141. https://doi. org/10.1007/BF01114537

44. Cossi M, Barone V, Cammi R, Tomasi J (1996) Ab initio study of solvated molecules: a new implementation of the polarizable continuum model. Chem. Phys. Lett. 255:327-335. https://doi.org/10. 1016/0009-2614(96)00349-1

45. Dong W, Yan M, Zhang M, Liu Z, Li Y (2005) A computational and experimental investigation of the interaction between the template molecule and the functional monomer used in the molecularly imprinted polymer. Anal. Chim. Acta 542:186-192. https://doi.org/ 10.1016/j.aca.2005.03.032

46. Frisch MJ et al (2009) Gaussian 09. Revision D.01 edn. Gaussian, Inc., Pittsburgh 